\title{
ANALISANDO SENTIMENTOS NO TRIPADVISOR: a v0z do consumidor como parâmetro decisório na medição da qualidade da informação em museus
}

\author{
SENTIMENT ANALYSIS IN TRIPADVISOR: the consumer's voice as a \\ decisive parameter in measuring the quality of information in museums
}

Larissa Fernandes Dutra ${ }^{1}$

Marlusa de Sevilha Gosling²

\begin{abstract}
RESUMO
0 objetivo deste artigo é identificar parâmetros que auxiliem gestores de museus na medição da qualidade da informação de suas instituições. Para isso, foram recuperadas 1900 avaliações em língua portuguesa, de setembro de 2017 a outubro de 2019 postadas na plataforma TripAdvisor, referentes ao Museu do Amanhã, localizado no Rio de Janeiro - RJ. A partir de uma análise de conteúdo foram excluídas as avaliações não relacionadas ao tema "informação museal”, restando 701 comentários. Através do sistema web iFeel, foram rodados 18 métodos diferentes de análise de sentimento e aplicados testes de assertividade em cada um deles. 0 método Umigon foi considerado o mais adequado na categorização de opiniões positivas, negativas e neutras para o banco de dados trabalhado. 0 maior número de sentimentos negativos a respeito da qualidade da informação no Museu do Amanhã relaciona-se a funcionários mal informados, a informação institucional desorganizada e a ausência de sinalização interna. Em se tratando de sentimentos positivos, percebeu-se que a relevância da informação transmitida pelas exposições e os altos níveis de interatividade para recuperação de informações do acervo foram os maiores favorecedores. Os resultados possibilitaram, ainda, a construção de parâmetros que poderão nortear tomadores de decisão de diversos outros museus quanto a temática qualidade da informação.
\end{abstract}

Palavras-chave: Qualidade da Informação. Museus. TripAdvisor. Análise de Sentimento. iFeel.

\begin{abstract}
The aim of this article is to identify parameters that assist museum managers in measuring the quality of information of their institutions. For this, 1,900 portuguese-language reviews were recovered from September 2017 to 0 ctober 2019 posted on the TripAdvisor platform, referring to the Museu do Amanhã, located in Rio de Janeiro - RJ. From a content analysis, reviews not related to the theme "museal information" were excluded, leaving 701 comments. Through the iFeel web system, 18 different methods of sentiment analysis were rotated and assertiveness tests were applied in each of them. The Umigon method was considered the most appropriate in the categorization of positive, negative and neutral opinions for the database worked. The greater number of negative feelings about the quality of information in the Museu do Amanhã relates to misinformed employees, disorganized institutional information and the absence of internal signaling. Regarding positive feelings, it was noticed that the relevance of information transmitted by the main exposure and the high levels of interactivity for retrieving information from the collection were the main favorors. The results also allowed the construction of parameters that can guide decision makers of several other museums regarding the theme quality of information.
\end{abstract}

Keywords: Information Quality. Museums. TripAdvisor. Sentiment Analysis. iFeel.

Artigo submetido em 22/07/2020 e aceito para publicação em 12/09/2020.

1 Doutoranda no Programa de Pós-Graduação em Gestão e Organização do Conhecimento da Universidade Federal de Minas Gerais, Brasil. ORCID https://orcid.org/0000-0002-2686-6975. E-mail: larissadutraa@gmail.com

2 Docente no Programa de Gestão e Organização do Conhecimento da Universidade Federal de Minas Gerais, Brasil. ORCID https:// orcid.org/0000-0002-7674-2866. E-mail: mg.ufmg@gmail.com 


\section{INTRODUÇÃ̃}

Segundo Godoy e Sanches (2014) é incontestável - principalmente se considerarmos as proporções econômicas mundiais que tomou o turismo cultural nos últimos anos - a necessidade de um trabalho de qualidade no sentido de nortear o consumidor de museus dentro do espaço museal. 0 atendimento e satisfação da necessidade de informação deste consumidor, desse modo, perpassa por uma responsabilidade da instituição que deve comunicar, com a devida clareza, todos os serviços ofertados por ela.

Em tese, podemos identificar dois tipos principais de informações em museus, sendo: 1) aquelas provenientes da exposição, de conteúdo variado, que permitem o aprendizado e a construção de novos conhecimentos e 2) aquelas ligadas à sua infraestrutura, que orientam e facilitam a visitação nessas instituições. Para Bevilacqua (2014), no entanto, é evidente a constatação da ausência de serviços de informação adequadamente organizados para responder às demandas de pesquisa e acesso do consumidor de museus, tanto em relação ao acervo quanto a suas instalações.

Por esse ângulo, percebe-se como pauta fundamental para os tomadores de decisão em museus, 0 entendimento da percepção dos seus consumidores quanto a qualidade da informação recuperada através dessas instituições. Por meio de pesquisas aplicadas com o público, por exemplo, é possível determinar quais aspectos precisam ser melhorados e quais estão de acordo com as necessidades do consumidor.

Atualmente, entretanto, pesquisas de opinião via questionário ou entrevista já não são 0 único meio de obtenção de informação oriunda do público, dado que, esses expressam, cada dia mais, suas opiniões e sentimentos espontaneamente na web. Essa opinião postada nas redes é de extrema importância, pois reflete um sentimento sem censura do indivíduo, que geralmente se mostra extremamente franco ao opinar sobre um produto ou serviço em redes sociais (SANTOS et al, 2010).

Um exemplo de opiniões expressas voluntariamente nas redes pode ser identificado através da plataforma TripAdvisor. Fundada nos anos 2000, se caracteriza como uma das maiores redes sociais para troca de informações sobre destinos turísticos no mundo e é alimentada pelos próprios consumidores a partir da avaliação quantitativa e qualitativa de produtos e serviços turísticos, facilitando o planejamento de viagens de visitantes diariamente. Dentre os recursos oferecidos pelo TripAdvisor, os usuários podem avaliar destinos, como os museus, distribuindo notas e registrando comentários. 
0 Museu do Amanhã, por exemplo, localizado na cidade do Rio de Janeiro, está também integrado ao TripAdvisor, recebendo centenas de avaliações diariamente. De acordo a descrição introdutória do Museu do Amanhã na plataforma TripAdvisor, a instituição é percebida por alguns como um "museu de informações", pois lida basicamente com ambientes audiovisuais imersivos, instalações interativas, jogos e experiências via inteligência artificial que induzem a um diálogo com o visitante. A instituição, nesse sentido, possui a informação como um dos pontos chaves de trabalho na construção de suas exposições, e é a partir daí que emerge 0 interesse de aplicação da presente pesquisa primeiramente neste museu, que conta com uma abrangente possibilidade de trabalho no que tange a estudos de qualidade da informação.

Desse modo, o objetivo do artigo é identificar parâmetros que auxiliem gestores de museus na medição da qualidade da informação de suas instituições, utilizando o Museu do Amanhã como espaço inicial para a aplicação da pesquisa. Para isso, realizou-se uma revisão de literatura relacionada a temática da qualidade da informação sendo as principais fontes de busca artigos, livros e dissertações recuperadas a partir de plataformas como o Portal de Periódicos CAPES/MEC, Google Scholar e 0 Web of Science, sem restrições de ano de publicação ou língua. Posteriormente foi construído um banco de dados preliminar com 1900 comentários relacionados ao Museu do Amanhã extraídos do TripAdvisor. A partir de então os comentários foram revistos por meio de uma análise de conteúdo no intuito de selecionar apenas aqueles que se enquadravam na temática "informação museal", restando 701 avaliações.

Em seguida optou-se pela utilização do sistema web iFeel para análise de sentimento dos 701 comentários de visitantes do Museus do Amanhã. Foram rodados todos os 18 métodos contemplados na ferramenta iFeel com o objetivo de detectar em qual deles seria observado maior rigor para a amostra de comentários rodada. Identificado o melhor método de trabalho (Umigon), seguiu-se para a verificação e análise dos resultados de pesquisa obtidos.

Por meio desta investigação foi possível determinar quais aspectos precisam ser melhorados em relação a qualidade da informação do Museu do Amanhã - RJ, mas ainda mais que isso, foi possível determinar parâmetros de análise em relação a temática da qualidade da informação em museus de uma forma mais ampla, que poderão ser trabalhados por outras instituições museais e seus gestores, podendo contribuir, consequentemente, na melhoria dos serviços de informação desses espaços. 


\section{DOS INFORMES BÁSICOS DE VISITAÇÃO ÀS PRERROGATIVAS DA DOCUMENTAÇÃO E RECUPERAÇÃO: O PAPEL DA INFORMAÇÃO NOS MUSEUS}

Ortega y Gasset em maio de 1935, na abertura do $2^{\circ}$ Congresso Internacional de Bibliotecas e Bibliografia na Espanha, pronunciou um discurso abrangente sobre cultura, experiência, ciência e sociedade (ORTEGA Y GASSET, 2006). Em um dos momentos de sua fala, proferiu a passagem do tigre na tentativa de elucidar - em uma referência a memória - a principal diferença entre animais e seres humanos:

0 tigre de hoje tem que ser tigre como se jamais houvesse existido tigre algum: não tira proveito das experiências milenares por que passaram seus semelhantes no profundo fragor das selvas. Todo tigre é um primeiro tigre: deve começar desde o princípio sua profissão de tigre. Mas o homem de hoje não começa sendo homem, mas, ao contrário, herda as formas de existência, as ideias, as experiências vitais de seus ancestrais e parte, portanto, do nível representado pelo passado humano acumulado sob seus pés (ORTEGA Y GASSET, 2006, sem paginação).

0 pensador, nesse sentido, afirma que a evolução ancestral desde o primeiro símio homo até os dias atuais permitiu o desenvolvimento das faculdades físicas e mentais humanas, o que possibilitou tanto a ampliação da nossa intelectualidade, quanto a habilidade de criação de ferramentas artificiais - que elevaram as competências naturais do homem, conferindo ao Homo sapiens versatilidade e competitividade. Assim, este ser aperfeiçoado ao longo de muitos anos adquiriu a capacidade de aprendizado com novas experiências, e por meio da linguagem e da escrita, sobretudo, foi capaz de disseminar socialmente 0 conhecimento armazenado.

Para a Ciência da Informação - Cl, segundo Barreto (2000) a memória aproxima-se ao conotativo de estoque de informação, como se fosse um conjunto de itens de informação organizadas (ou não) e com conteúdo de interesse de uma ou várias comunidades de receptores. Assim, uma das maneiras que o homem utiliza para salvaguardar a memória humana, transferindo conhecimento entre gerações é por meio de instituições como os museus. Para Monteiro (2014), os museus devem ter como missão a preservação e promoção do acesso às informações da memória registrada, residindo aí a sua função social.

0 acervo museal, desse modo, constituído de heranças simbólicas materializadas em textos, monumentos, documentos e objetos diversos, funciona como um gatilho para acionar significados associados ao que passou, fazendo com que os museus detenham forte ligação com a criação e desenvolvimento do conhecimento social humano. Isso porque, o acervo contém, enraizado em si, uma junção de memórias que carregam o conhecimento e a identidade social de diferentes povos e a partir 
da representação e transmissão de informações através desses artefatos, são gerados novos estados e formatos de conhecimento, garantindo um ciclo de evolução sociocultural e, consequentemente, assegurando a evolução do próprio ser humano (DUTRA; BARACHO, 2020).

Para isso, o caminho quotidiano repleto de atividades que os profissionais de museus precisam trilhar até que um objeto seja representando e apresentado ao público da forma que o vemos - e que a sua informação seja recuperada pelos consumidores - é denominado documentação (MONTEIR0, 2014). Segundo Ceravolo (2014) o documentalista age de forma a imprimir direção ao que está implícito, traduzindo, cada objeto, em esquemas classificatórios, organizando o conhecimento social.

Assim, em uma exposição, por exemplo, quando se tem acesso as obras, objetos e monumentos, observa-se a presença de pequenas etiquetas, legendas ou textos (e hipertextos) nos quais se leem explicações referentes ao produtor da obra, data, técnica, composição material, utilidade, simbolismo, etc. Por vezes, há vídeos, filmes e outras mídias como complementação, ou, então, elas mesmas se constituem como acervos. Esses registros, se configuram como metadados e ali estão porque foram coletados, registrados e organizados. Desse modo, o objeto museológico, entre suas várias facetas, pode ser percebido como uma matriz geradora de informação para o consumidor de museus e a instituição museológica, consequentemente, se torna unidade de informação sociocultural (CERAVOLO, 2014, p. 81).

Nessa perspectiva, para Bearman (2014) quando pensamos em museus, o foco na qualidade das informações transmitidas para o consumidor é uma das estratégias mais válidas, a longo prazo, para o sucesso dessas instituições. Isso porque, se os museus são respeitados mundialmente pela chancela de qualidade, autenticidade e veracidade das suas informações é premissa básica que essas sejam organizadas e transmitidas com qualidade para o seu público. Nessa perspectiva, 0 autor retrata que alguns pontos em específico contribuem para a qualidade da informação em exposições museais, sendo eles: a) contextualização; b) relevância; c) acessibilidade; d) interatividade e e) sinergia.

Do ponto de vista da contextualização, Bearman (2014) comenta que ao coletar material, os museus retiram objetos culturais do contexto de sua descoberta ou uso. A primeira obrigação dos documentalistas perante seus usuários, portanto, é a de recontextualizar seu acervo para que este possa ser compreendido. Assim, o consumidor final poderá entender por que determinado objeto fora alocado em determinado repositório e qual a sua significância social. Em se tratando de relevância, entende-se que é importante reconhecer as necessidades e interesses das diferentes audiências do museu. Compreendendo o tipo de consumidor de cada uma dessas instituições teremos a ideia da 
relevância que será percebida em se tratando das exposições elaboradas pelo museu. A relevância, leva, inclusive, a reflexão sobre roteiros personalizados, dedicados a preferência de cada espectador.

No caso da acessibilidade, ressalta-se a necessidade dos mais variados canais e veículos de informação para os diferentes tipos de consumidores, incluindo aqueles com necessidades especiais. 0 autor salienta ainda o uso dos museus virtuais ou simplesmente das páginas de museus na web como repositórios de informações específicas de cada museu, permitindo que mesmo aqueles consumidores que estejam distantes geograficamente desses espaços consigam acessar o seu conteúdo. Por interatividade, Bearman (2014) considera o artifício das tecnologias da comunicação e da informação - TIC como possibilitadoras de interações com o consumidor. Utilizando recursos de voz, inteligência artificial, games e até robótica, a informação em museus poderá ser transmitida com maior fluidez e instintividade, contribuindo para aumentar os níveis de qualidade da representação e recuperação de informações. Quanto a sinergia, o autor comenta sobre as possibilidades advindas da web, que poderiam, por exemplo, trazer a ideia de um repositório digital universal de cultura, ou a catalogação do conteúdo de museus na forma de dados abertos vinculados. 0 autor ainda inclui a perspectiva de dados atualizados em tempo real em museus, que poderiam ser extraídos facilmente via web, levando informação em tempo real para os consumidores, por exemplo.

Por outro lado, para Godoy e Sanches (2014) é ainda de extrema importância ressaltar, que não somente pelas exposições e pela ação documental são recuperadas informações em museus, já que, a experiência com a visita a essas instituições perpassa também por questões relacionadas a acesso, sinalização, atendimento de funcionários, material informativo e a sua infraestrutura de uma forma geral.

Assim, segundo os autores, é fundamental que, por exemplo, esteja claro o modo como se pode adquirir os ingressos ou os descontos (no caso de serem museus pagos), ou se a sua entrada é gratuita; avisar se há banheiros e fraldários em pontos do trajeto das exposições ou em lugares específicos; se possuem acesso para portadores de necessidades especiais; sinalizar se, ao longo do espaço de visitação, há lugares reservados com cafeterias; se é permitido fotografar o acervo ou parte dele, e outros tipos de regras a serem observadas; se há terminais com internet disponíveis ao público, etc. Esse conjunto de serviços de informação permitirá que se evitem surpresas desagradáveis, haja menos conflitos ao longo da permanência no museu e se crie uma conexão com as informações relacionadas ao acervo propriamente dito.

Para Godoy e Sanches (2014), nesse sentido, é incontestável - principalmente se considerarmos as proporções econômicas mundiais que tomou o turismo cultural nos últimos anos no mundo - a 
necessidade de um trabalho de qualidade no sentido de nortear o consumidor de museus dentro do espaço museal. 0 atendimento e satisfação da necessidade de informação por parte do consumidor, nesse sentido, perpassa por uma responsabilidade da instituição que deve comunicar, com a devida clareza, todos os serviços ofertados por ela.

Assim, ao tratar a temática da qualidade da informação em museus deve-se levar em consideração tanto as necessidades funcionais e logísticas de visitação - ligadas a informação infraestrutural quanto os sistemas de informação que tangem às prerrogativas da representação e recuperação para a construção do conhecimento social - ligadas a informação expográfica, conforme vimos anteriormente. Desse modo, de uma forma geral, pode-se inferir que existem dois tipos principais de informações em museus, sendo: 1) aquelas provenientes da exposição, de conteúdo variado, que permitem 0 aprendizado e a construção de novos conhecimentos e 2) aquelas ligadas à sua infraestrutura, que orientam e facilitam a visitação dos consumidores dessas instituições.

Para Bevilacqua (2014), no entanto, ainda nos dias atuais é evidente a constatação da ausência de serviços de informação adequadamente organizados para responder às demandas de pesquisa e acesso, tanto em relação ao acervo do museu quanto a suas instalações. Segundo o autor, mesmo contando com departamentos específicos de documentação, os museus, em sua vasta maioria, ainda não estão estruturados para atender demandas de informação e pesquisa sobre as suas próprias coleções para o público interessado em geral, limitando-se a disponibilizar apenas catálogos informatizados com informações básicas sobre o seu acervo em sua página na internet.

Segundo Godoy e Sanches (2014), de acordo com pesquisas desenvolvidas pelo Grupo de Pesquisa Turismo e Cultura - TCult, da Universidade Federal Fluminense, consumidores entrevistados revelaram que não conseguiram obter informações suficientes sobre os museus visitados, fator atribuído tanto à carência de divulgação de ambientes de circulação de informações - seja pelo site institucional do museu ou no próprio trade turístico - quanto pelo fato de não haver, no caso de turistas estrangeiros, textos vertidos para outros idiomas. Em conclusão aos seus estudos, os autores reforçaram que não faz sentido preservar objetos, peças e documentos, se eles, por inúmeros fatores, não conseguirem informar ao público.

Por esse ângulo, percebe-se como pauta fundamental para os tomadores de decisão em museus, 0 entendimento da percepção dos seus consumidores quanto a qualidade da informação recuperada através dessas instituições. Por meio de pesquisas com o público, por exemplo, é possível determinar quais aspectos precisam ser melhorados em relação a esta perspectiva e quais estão de acordo com as necessidades do consumidor. 
Autores como Mattera (2014) e Marchiori (2014) enfatizam, nesse sentido, que dados recolhidos diretamente com o consumidor de um determinado bem ou serviço são recursos indispensáveis para decisões sobre novas facetas a explorar, a melhoria de serviços de uma forma geral e, consequentemente, a obtenção de vantagem competitiva. Para as autoras, a importância de se obter uma vantagem competitiva se dá, principalmente, pela segurança em relação à direção do próprio negócio, ou seja, para onde e de que forma a instituição deve caminhar.

No caso do presente estudo, apresentaremos nas próximas seções dados obtidos por meio da mineração de comentários na web através do portal TripAdvisor que poderão contribuir significativamente para as análises e decisões dos gestores de museus em se tratando da qualidade da informação dessas instituições.

\section{TRIPADVISOR E ANÁLISE DE SENTIMENTO: A MINERAÇÃO DE COMENTÁRIOS NA WEB PARA MEDIÇÃO DA QUALIDADE DA INFORMAÇÃO EMM MUSEUS}

Com a utilização significativa da web nos últimos anos, empresas e instituições diversas tem buscado novas formas de detectar, por parte de seus consumidores, retornos quanto a seus produtos e serviços. Segundo Santos et al (2010) a pesquisa de opinião com questionário ou entrevista - que objetiva identificar os pontos fortes e fracos de determinados serviços e possíveis melhorias - já não é o único meio de obtenção de informação oriunda do consumidor, dado que, atualmente, esses expressam espontaneamente suas opiniões e sentimentos na web.

Essa opinião postada nas redes é de extrema importância, pois reflete o sentimento sem censura do usuário, que por outro lado, quando da participação de entrevistas, por exemplo, pode ser reprimido se colocado face-a-face com pesquisadores contratados ou até mesmo com os próprios gestores das organizações. Santos et al (2010) comentam, inclusive, que através de uma entrevista direta com a pessoa, existe a possibilidade do sentimento de intimidação, o que vai na contramão dos comentários na internet, que geralmente são constituídos por extrema franqueza.

Críticas, comentários e outras formas de análise de produtos e serviços se encontram disseminados na internetem vários tipos de páginas, variando de blogs pessoais a sites de recomendação e compras. Um exemplo pode ser identificado através da plataforma TripAdvisor. Fundada nos anos 2000, se caracteriza como uma das maiores redes sociais para troca de informações sobre destinos turísticos no mundo e é alimentada pelos próprios consumidores a partir da avaliação quantitativa e qualitativa de produtos e serviços turísticos, facilitando o planejamento de viagens de visitantes diariamente (TRIPADVISOR, 2019). 
De acordo com o seu site, o TripAdvisor recebeu em 2016 cerca de 340 milhões de visitantes mensais e, atualmente, em 2019, conta com uma média de 460 milhões de usuários a cada mês. Além disso, já são 830 milhões de avaliações e opiniões sobre mais de 8,6 milhões de empresas, dentre elas, hotéis, restaurantes, museus, centros de cultura e muitos outros atrativos turísticos, tornando-se um grande banco de dados com informações relevantes para elaboração de estratégias de desenvolvimento de empresas de diferentes ramos de atividade. Além disso, o site se encontra disponível em 28 idiomas.

Dentre os recursos oferecidos, os usuários podem comparar preços e reservar hotéis, casas de temporada, voos e passeios de forma online, receber recomendações de destinos e meios de hospedagem a partir do perfil do usuário, publicar fotos de viagens, interagir através de fórum de perguntas e dúvidas para cada destino, buscar locais e atrações a partir de mapas virtuais e principalmente avaliar os produtos e destinos distribuindo notas e registrando comentários.

Os comentários e opiniões dos usuários do TripAdvisor possuem não só componentes quantitativos (posições em rankings, avaliações, número de comentários, etc.), mas também informações qualitativas, possibilitando ao proprietário de um estabelecimento, por exemplo, identificar o que os seus clientes estão dizendo sobre seu negócio. Para Oliveira (2017) aqueles que processarem as informações e opiniões de seus fregueses de forma assertiva poderão ampliar os processos de melhoria das suas instituições. Isso é de grande valia para os gestores que veem, por exemplo, vantagem em se ter informações na ponta dos dedos e de forma gratuita, como é o caso do TripAdvisor.

Para avaliar uma atração no TripAdvisor, como um museu, por exemplo, o usuário deve entrar com 0 seu login e senha no site e, de forma obrigatória, dar uma nota de satisfação para a atração numa escala de 1 a 5 (sendo 1 = horrível, 2 = ruim, 3 = razoável, 4 = muito bom e 5 = excelente), escrever um comentário com, no mínimo, 100 caracteres, responder a pergunta sobre que tipo de visita realizou (casal, família, amigos, negócios ou sozinho) e qual foi o mês (sendo possível escolher 1 entre os últimos 12 meses do ano corrente).

Observa-se, desse modo, que com o aumento do número de usuários do TripAdvisor nos últimos anos - conforme visto anteriormente - e, consequentemente, o crescimento do número de comentários na plataforma, a produção de dados não estruturados - como as avaliações escritas - prospera a passos largos, exigindo dos sistemas um esforço maior para a coleta, recuperação e análise de conteúdos que promovam a inteligência competitiva e tomada de decisões pelas instituições. Isso ocorre, pois com dados organizados em um modelo conceitual a informação pode ser recuperada por consultas em linguagem padrão, entretanto, para dados não estruturados, como um texto ou comentário na internet, que contém informação ambígua e carregada de sentimentos e ruídos, a análise pelas máquinas é vista como um desafio ainda maior. 
De acordo com Junior (2017) é crescente o número de trabalhos que procuram extrair informação e conhecimento a partir de textos publicados na web, o que vem, de certa forma, impulsionando a pesquisa em processamento de linguagem natural e mineração textual, surgindo daí o método de análise de sentimento. Para Liu (2010) a análise de sentimento surge como 0 estudo computacional das opiniões, avaliações e emoções das pessoas, expressas em textos, relativas a entidades, eventos e seus atributos. A análise de sentimento, nesse sentido, é usada em sistemas onde é necessário saber a opinião de indivíduos para, principalmente, tomar decisões face a diferentes domínios, como finanças - para identificar fatores de risco; política - para mapear intenções de voto; marketing - para detectar a satisfação de um produto ou serviço, e outros.

Para Santos et al (2010), a análise de sentimento ou mineração de opinião é um ramo da mineração de textos preocupado em classificar textos não por tópicos, mas sim pelo sentimento ou opinião contida. Geralmente estão associados a classificação binária entre sentimentos positivos e negativos, podendo acrescer da opinião "neutra".

Um contraponto acerca do método de análise de sentimento relatado por Junior (2017) baseiase nos diferentes contextos empregados em cada comentário, fazendo com que esses possam ser de caráter positivo ou negativo dependendo, por exemplo, do ponto de vista. Para o autor, um comentário referindo-se a chuva em uma determinada região pode ser positivo para o contexto do agronegócio e negativo para o domínio do turismo, sendo necessária uma análise criteriosa do pesquisador que os estiver julgando. Junior (2017), nesse sentido, revela a necessidade da aplicação de testes que direcionem o método mais adequado para a análise de sentimento em um determinado contexto, evitando resultados de pesquisa contestáveis e enviesados.

Desse modo, o monitoramento do comportamento dos usuários em plataformas como o TripAdvisor, pode ser de grande serventia na elaboração de estratégias que contribuam na melhoria do atendimento e da satisfação dos consumidores de museus, por exemplo. Essas estratégias podem ser trabalhadas em diferentes perspectivas, inclusive, naquela que diz respeito a qualidade da informação proveniente dessas instituições.

0 Museu do Amanhã, por exemplo, localizado na cidade do Rio de Janeiro e fundado em dezembro de 2015 pela Prefeitura do Rio, está também integrado a plataforma TripAdvisor, recebendo centenas de avaliações diariamente. Segundo seu site institucional, esse se configura como um novo tipo de museu de ciências onde 0 visitante é convidado a examinar o passado, conhecer as transformações atuais e imaginar cenários possíveis para os próximos 50 anos (MUSEU DO AMANHÃ, 2019). De acordo a descrição introdutória do Museu do Amanhã na plataforma TripAdvisor, a instituição é percebida por alguns como um “museu de informações", pois 
lida basicamente com ambientes audiovisuais imersivos, instalações interativas, jogos disponíveis ao público em português, inglês e espanhol e experiências como a da IRIS+, desenvolvida através de inteligência artificial, que permite dar respostas as dúvidas do visitante e também fazer perguntas, guiando um diálogo sobre os dois eixos temáticos principais do museu: sustentabilidade e convivência, dentre muitas outras possibilidades.

Vê-se, nesse sentido, que o Museu do Amanhã é um museu que lida fortemente com informação e conhecimento, já que, possui uma expografia baseada, principalmente, na representação de informações e dados por meio de diferentes possibilidades tecnológicas, como computadores, telas variadas, totens, etc. Pode-se entender, nesse sentido, que o Museu do Amanhã possui a informação como um dos pontos chaves de trabalho na construção de suas exposições, e é a partir desse olhar que emerge 0 interesse de aplicação da presente pesquisa, primeiramente, neste museu, que conta com uma abrangente possibilidade de trabalho no que tange a qualidade da informação.

\section{METODOLOGIA}

Os passos metodológicos desta investigação se resumem em oito momentos principais (Figura 1):

Figura 1 - Passo a passo metodológico
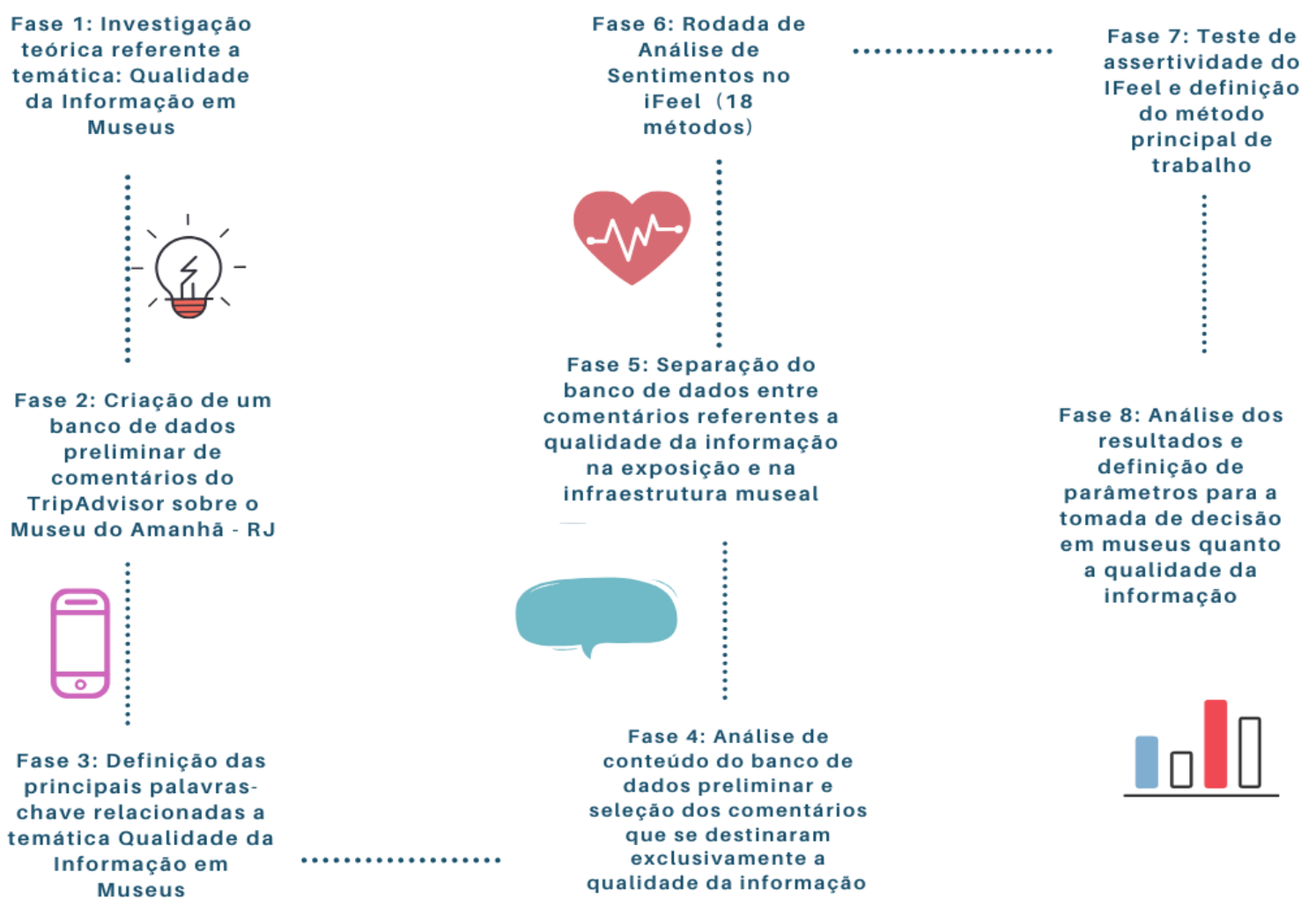

Fonte: Elaboração própria (2019). 
Inicialmente foi realizada uma revisão de literatura relacionada a temática da qualidade da informação em museus, conforme apresentada nas seções anteriores. As fontes de pesquisa foram artigos diversos, livros e dissertações recuperadas a partir de plataformas como o Portal de Periódicos CAPES/MEC, Google Scholar e o Web of Science, sem restrições de ano de publicação ou língua. A partir da leitura do resumo e título de cada investigação, essas foram definidas como apropriadas para nos auxiliar no desenvolvimento da presente pesquisa ou não.

Na fase 2 foi construído um banco de dados preliminar com comentários relacionados ao Museu do Amanhã extraídos do TripAdvisor. Foram recuperados 1900 comentários em língua portuguesa de Setembro de 2017 a Outubro de 2019 de turistas e visitantes de localidades diversas, como Salvador BA, Botucatu - SP, Belo Horizonte - Minas Gerais e outros.

Na sequência, foram definidas - mediante as investigações previamente estudadas na Fase 1 - as principais palavras-chave relacionadas a temática da qualidade da informação em museus para que, então, fosse possível a exclusão daqueles comentários que não seriam úteis para a análise final deste artigo, ou seja, aquelas opiniões que não se destinavam a assuntos relacionados a qualidade da informação museal. As palavras-chave selecionadas foram: conteúdo, conhecimento, dado, acervo, exposição, assunto, tema, sinalização e informação. A partir de então todos os 1900 comentários foram revistos por meio de uma análise de conteúdo no intuito de selecionar apenas aqueles que se enquadravam na temática abarcada pelo artigo. Um exemplo de comentário retirado da base de dados é explicitado a seguir:

Novo ícone da Cidade Maravilhosa, o Museu do Amanhã, localizado na Praça Mauá, é um dos principais pilares do Porto Maravilha, ganhou cara nova e se tornou mais um cartão postal do Rio (Visitante de Varginha, MG - Março, 2018).

Por mais que o comentário acima se refira a beleza do Museu do Amanhã e a sua importância para a revitalização da área portuária do Rio de Janeiro, não acrescentaria nos resultados esperados pelo presente estudo. Outro tipo de comentário retirado da base de dados se refere àqueles visitantes que não chegaram a conhecer o museu internamente, mas somente o seu exterior, abordando aspectos relacionados mais a arquitetura da instituição do que seu conteúdo de fato:

\footnotetext{
Apesar de não ter visitado internamente o Museu do Amanhã, a parte externa é muito linda! Vale a visita e a vista que tem da ponte Rio-Niterói. E a arquitetura futurista do lugar é impressionante! (Visitante de Aracaju, SE - Novembro, 2017).
}

Assim, após a exclusão das avaliações não pertinentes para o desenvolvimento da pesquisa, restaram 701 comentários sendo 603 relacionados a qualidade da informação da exposição e 98 
relacionados a qualidade da informação da infraestrutura do Museu do Amanhã. A diferença de conteúdo entre os dois tipos de comentários pode ser observada a seguir:

A exposição permanente é interessante, mas falta algo de mais concreto, as informações estão soltas e não conectadas entre si! Parece mais uma lição de moral sobre ecologia do que um informativo mais sólido. (Visitante de Salvador, BA - Janeiro, 2018).

Não existe informação. Você entra no museu e fica completamente perdido. Não existe um guia de bolso para olhar as atrações do museu. Você realmente nunca saber pra onde ir. (Visitante de Botucatu, SP - Março, 2019).

Após a definição dos dois bancos de dados finais a serem analisados (qualidade da informação da exposição e qualidade da informação infraestrutural), optou-se pela utilização do sistema web iFeel para análise de sentimento dos comentários recuperados do TripAdvisor. 0 iFeel consiste em uma ferramenta que permite a comparação do resultado de sentimentos para vários métodos. O sistema, segundo Araujo, Gonçalves e Benevenuto (2013) auxilia pesquisadores e empresas na análise de sentimentos referente aos mais variados assuntos, permitindo acesso a 18 métodos diferentes como Emoticons, SentiStrenght, SentiWordNet, SASA, Umigon, Happiness Index, Panas-t, e outros.

Assim, na Fase 6 de pesquisa, os 18 métodos de análise de sentimento abarcados na ferramenta iFeel foram rodados, separadamente, entre os dois bancos de dados trabalhados nesta investigação. Para detectar qual seria o melhor método de trabalho em relação aos bancos de dados analisados, foi elaborado um teste de assertividade (Fase 7) no intuito de identificar em qual dos 18 métodos seria observado maior rigor para a amostra de comentários rodada.

0 teste foi realizado em 200 dos 701 comentários (28\% da amostra) e baseou-se na leitura das avaliações comparando o resultado obtido por cada método com o que era de fato realidade para aquele comentário. Um exemplo de como foi realizado o teste pode ser observado na Tabela 1 que descreve a opinião de um visitante de Ribeirão Preto - SP, onde aqueles métodos que obtiveram resultados diferente do esperado foram sinalizados com farol vermelho e os que obtiveram resultados dentro do que era esperado foram sinalizados com farol verde. 
Tabela 1 - Teste de rigor dos métodos de Análise de Sentimento do sistema iFeel

\begin{tabular}{|c|c|c|c|}
\hline $\begin{array}{l}\text { No interior, muita } \\
\text { mostrar de tudo u } \\
\text { interna confusa. At } \\
\text { retornar ao local ( }\end{array}$ & $\begin{array}{l}\text { tecnia expositiva, } \\
\text { ouco e acabando p } \\
\text { imento dos funcion } \\
\text { ante de Ribeirão Pre }\end{array}$ & $\begin{array}{l}\text { Is um conteúdo sem } \\
\text { mostrar muito pouce } \\
\text { os extremamente disp } \\
\text {, SP - Dezembro, } 201\end{array}$ & $\begin{array}{l}\text { uito foco, tentand } \\
\text { le tudo. Sinalizaçã } \\
\text { cente. Não pretend }\end{array}$ \\
\hline Método & Resultado obtido & Resultado Esperado & Resultado Teste \\
\hline OPINIONLEXICON & Neutro & Negativo & \\
\hline SENTISTRENGTH & Positivo & Negativo & \\
\hline SOCAL & Negativo & Negativo & \\
\hline HAPPINESSINDEX & Positivo & Negativo & \\
\hline EMOTICONSDS & Positivo & Negativo & \\
\hline SANN & Negativo & Negativo & \\
\hline SENTIMENT140 & Negativo & Negativo & \\
\hline STANFORD & Negativo & Negativo & \\
\hline AFINN & Positivo & Negativo & \\
\hline MPQA & Negativo & Negativo & \\
\hline NRCHASHTAG & Negativo & Negativo & \\
\hline EMOLEX & Positivo & Negativo & \\
\hline EMOTICONS & Neutro & Negativo & \\
\hline PANAST & Positivo & Negativo & \\
\hline SASA & Positivo & Negativo & \\
\hline SENTIWORDNET & Positivo & Negativo & \\
\hline VADER & Positivo & Negativo & \\
\hline UMIGON & Negativo & Negativo & \\
\hline
\end{tabular}

Fonte: Elaboração própria (2019). 
A partir da realização do teste, verificou-se que o método Umigon foi 0 de maior assertividade com $72 \%$ de resultados corretos, daí a opção pela sua utilização. Métodos como Panas-t, Happiness Index e SASA tiveram mais de 60\% de discrepância, por exemplo. Isso ocorre, devido ao fato de que alguns métodos são mais adequados para determinados tipos de conteúdo. 0 Emoticons, por exemplo, baseia-se exclusivamente na análise de emoticons - desenhos que, em alguns casos são baseados em faces humanas e que podem expressar sentimentos de felicidade ou tristeza. Assim, para determinar variações de humor para comentários extraídos da web analisa-se a expressão de polaridade negativa ou positiva do desenho (GONÇALVES et al, 2019). No caso de plataformas como o TripAdvisor, por exemplo, em que o consumidor não possui a possibilidade de inserção de emoticons, o método não é bem aplicável.

0 Umigon, por outro lado, foi proposto, em sua origem, para a detecção de sentimentos na rede social Twitter, inclusive sentimentos de subjetividade. Para isso, o método utiliza diversos recursos linguísticos como onomatopéias, exclamações, emoticons, etc. Ele possui heurísticas responsáveis para disambiguar o texto baseado em negações, palavras alongadas e hashtags. Em geral, as heurísticas baseiam-se em pistas gramaticais e sintáticas que mudam a intensidade do sentimento e vão além da simples soma de pontuações. Dentre elas destacam-se: 1) Pontuação (número de exclamações ao final de uma frase por exemplo); 2) Capitalização ("EU ODIEl”, por exemplo, é mais intenso do que “eu odiei”); 3) Negações e Intensificadores ("0 serviço não é bom” é negativo enquanto "0 serviço é muito bom" é muito positivo); 4) Conjunção "mas" que muda a polaridade; 5) Trigrama para identificar negações mais complexas (por exemplo “A comida aqui não é assim tão boa”), etc.

Assim, identificado o melhor método de trabalho, seguimos para a verificação dos resultados de pesquisa obtidos com a análise de sentimento dos consumidores do Museu do Amanhã - RJ em relação a qualidade da informação desta instituição.

\section{RESULTADOS}

Conforme Gráfico 1, dos 98 comentários referentes a qualidade da informação quanto a infraestrutura do Museu do Amanhã - RJ, 54\% possuem um sentimento negativo, 38\% positivo e 8\% neutro. Em se tratando dos comentários de cunho "neutro" a maioria se destinou a falar sobre 0 ingresso do museu, que pode ser comprado via site com antecedência e evita filas na entrada, o que é uma informação importante, principalmente para aqueles que visitarão o museu em dias em que 
a cidade está normalmente mais cheia, como em vésperas de feriados e grandes eventos. Sobre as avaliações positivas (38\%), a maioria dos consumidores se destinou a exaltar os guias e instrutores da instituição como pessoas bem informadas, além de revelarem satisfação com os níveis de acessibilidade dos informes museais - escritos em três línguas (português, inglês e espanhol).

Quanto aos comentários de sentimento negativo (54\%), a maioria desses (21\%) ressalta a falta de informação dos funcionários do museu de uma forma geral - portaria, atendimento, segurança, etc. Uma visitante de Belo Horizonte - MG fez o seguinte comentário:

Tenho prótese e tenho direito a meia entrada, apresentei o documento comprovando, porém, a funcionária não o aceitou, apesar da página do museu informar que não é necessário comprovar, apenas se autodeclarar. Sugestão: colocar atendentes diferenciados para atendimento preferencial devidamente treinados e mais informados (Visitante de Belo Horizonte, MG Setembro, 2019).

Pelo comentário da consumidora, a insatisfação se dá principalmente pela falta de informação da atendente da bilheteria do museu, que não possui a informação de que pessoas com necessidades especiais tem o direito - segundo o site da instituição - de pagar a meia entrada, o que gerou um desconforto por parte da visitante. 0 segundo quesito que levou a um sentimento negativo quanto a qualidade da informação infraestrutural do Museu do Amanhã - RJ, com 16\% do total se baseia na informação institucional desorganizada. Um visitante de Recife - PE, fez o seguinte comentário:

0 museu ficou fechado durante o feriado de carnaval e assim ficará até quinta-feira. Estranho que não há aviso no site. Meio absurdo numa época de turismo intenso (Visitante de Recife, $\mathrm{PE}$ - Março, 2019)

Ou seja, durante o período de carnaval, turistas chegaram a se deslocar para o museu, contudo, como a informação via site não estava atualizada, muitos deles não sabiam sobre o fechamento da instituição no período. Alguns outros comentários relataram o mesmo problema em se tratando do Museu do Amanhã - RJ. 
Gráfico 1 - Análise de Sentimento quanto a qualidade da informação infraestrutural do Museu do Amanhã - RJ

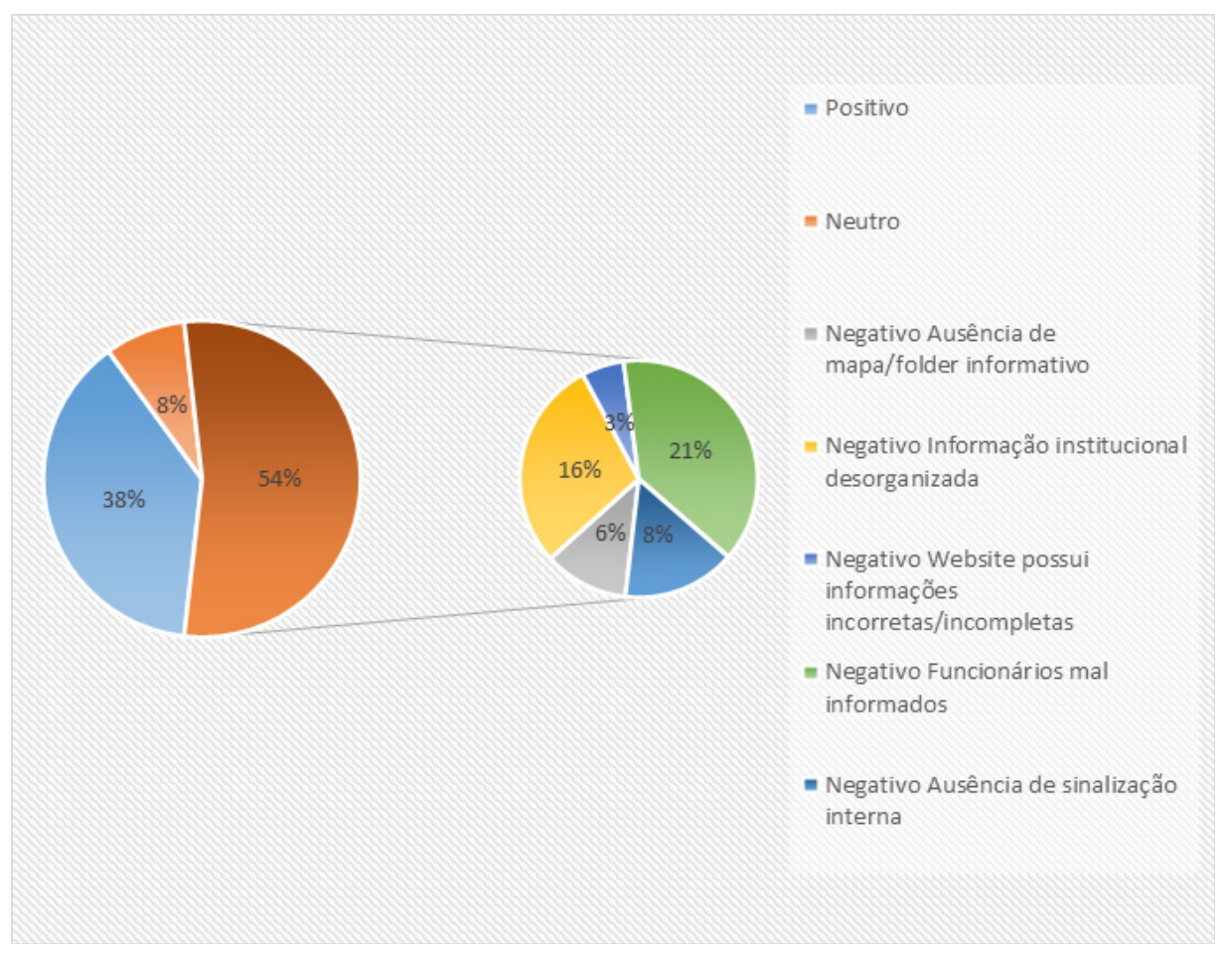

Fonte: Elaboração própria (2019).

Em terceiro lugar, com 8\% dos comentários negativos percebe-se a insatisfação com a sinalização interna do museu. Um visitante de Brasília - DF, ressalta que ficou perdido dentro da instituição, sem saber qual o local do início da exposição, questionando exatamente a falta de sinalização no local:

Falta um pouco mais de explicação para onde temos que ir de início. Vc passa pelos locais de entrada da exposição, segunda, terceira, etc, exposição sem saber se entra ou não! Achamos que faltou uma sinalização mais clara (Visitante de Brasília, DF - Abril, 2018).

Ainda sobre o sentimento negativo nos comentários da qualidade da informação infraestrutural do Museus do Amanhã, $6 \%$ dos visitantes perceberam a ausência de mapa ou folder informativo que conseguisse auxiliar nos caminhos de visitação, e, por fim, $3 \%$ dos consumidores relataram que 0 website do museu possui alguma informação incorreta e/ou incompleta. Quanto a ausência de mapas e folders informativos, o comentário abaixo foi selecionado para exemplificação do sentimento negativo sobre este aspecto:

Senti falta de um roteiro de visita, tipo mapa do local. Sem este roteiro o visitante fica meio perdido. Normalmente tem um no início, senti falta deste tipo de informação. A recepção do Museu decepciona, pois não há explicação alguma, nem folders ou mapas de exposição! Fui com filha adolescente e outra criança (Visitante de Bento Gonçalves, RS - Janeiro, 2019). 
Em se tratando da análise de sentimento quanto a qualidade da informação no Museu do Amanhã relacionada a exposição, percebe-se, conforme Gráfico 2, que as avaliações foram mais positivas do que negativas, quando comparamos a qualidade da informação infraestrutural do museu. Isso porque, dos 603 comentários analisados, 53\% tiveram um sentimento positivo, 26\% neutro e 21\% negativo.

Em se tratando dos comentários de cunho neutro, a maioria aborda os temas das exposições que visitaram, as possibilidades de interação com tecnologia em um sentido mais descritivo da visita, como pode ser observado no comentário abaixo:

0 percurso a ser feito lá dentro é basicamente de um corredor, com nichos de exposições, abertos ou fechados, em geral com monitores para exibir as informações (Visitante de Araxá, $M G$ - Dezembro, 2018).

Por mais que um comentário de cunho neutro pareça não contribuir para a definição de parâmetros que lidem com a qualidade da informação em museus, através deles, é possível recuperar opiniões que agreguem o conhecimento de mercado dos gestores dessas instituições, que conseguirão identificar, o que tem chamado mais atenção a do público em se tratando da expografia do museu, por exemplo.

Gráfico 2 - Análise de Sentimento quanto a qualidade da informação relacionada a exposição do Museu do Amanhã - RJ

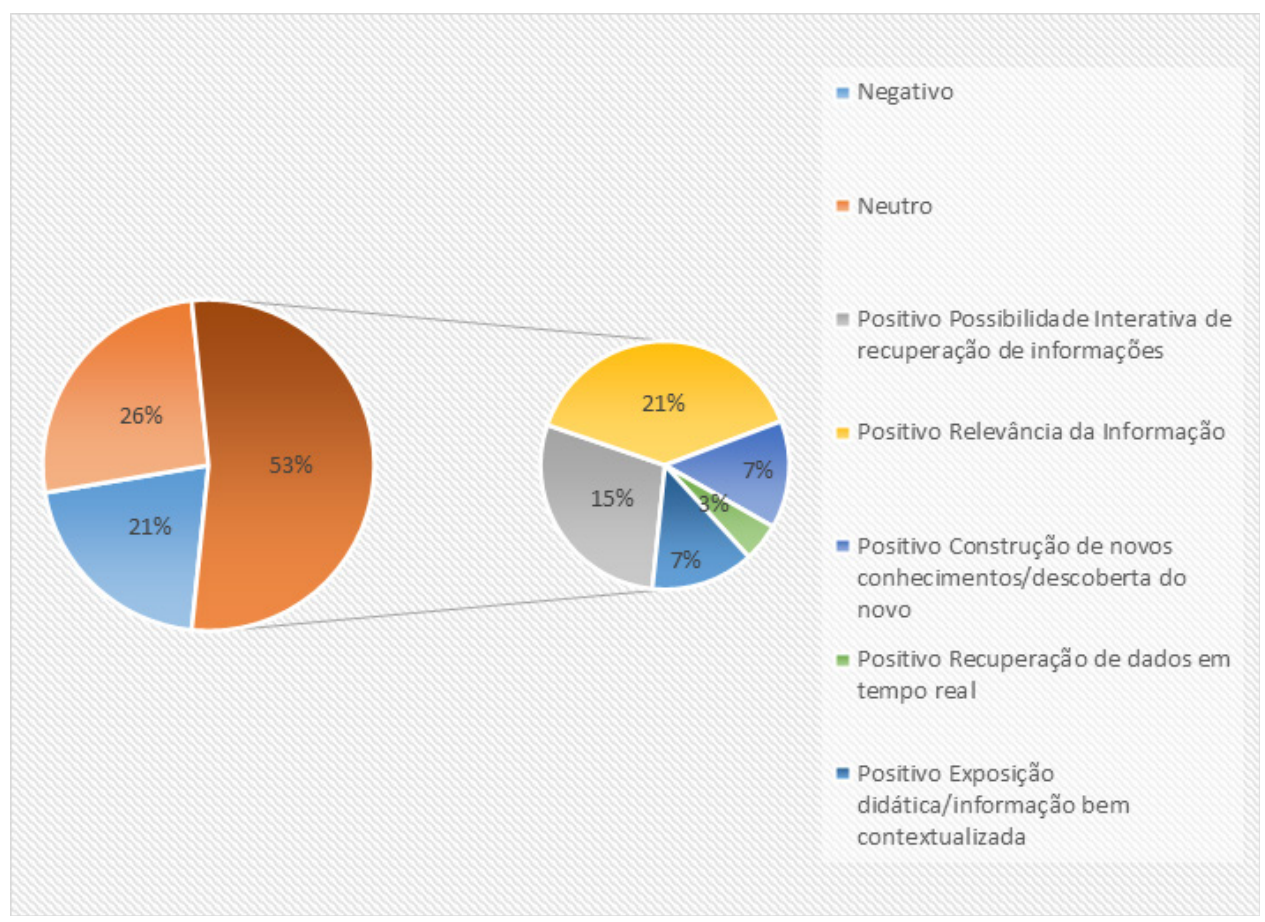

Fonte: Elaboração própria (2019). 
Quanto aos comentários de cunho negativo (21\%), identifica-se que muitos visitantes acharam inadequado o conteúdo exposto pelo museu, alegando serem informações que podem ser acessadas através de qualquer dispositivo com internet, ou seja, não conseguiram perceber agregação de conhecimento pela exposição. Alguns, inclusive, questionaram a expografia museal, com muito texto para se ler "em pé", deixando a visita desconfortável. Alguns exemplos podem ser verificados a seguir:

E dá-Ihe textos tirados da Internete até programas da Globo News, tudo apresentado de forma «moderna», exposições com muitas telas e alguma interatividade. Prova de que embalagens legais as vezes são apenas um disfarce para ideias banais (Visitante de Conceição do Mato Dentro, MG - Outubro, 2017).

Várias dessas informações podem ser acessadas em qualquer dispositivo conectado à internet, sem que seja necessário se submeter a uma "aventura" para chegar lá - causam uma impressão que se foi feito "muito barulho por nada" (Visitante de São José do Rio Preto, SP - Outubro, 2018).

Dos $53 \%$ de comentários de cunho positivo, 21\% alegaram que a informação apresentada pela instituição é de grande relevância, daí a percepção da sua qualidade. Em segundo lugar, 15\% enalteceram a possibilidade interativa de recuperação de informações através da exposição. Conforme dito anteriormente, o museu oferece momentos de diálogo com a IRIS+ (inteligência artificial) e outras tecnologias que levam a grande interatividade com o público. Para esta amostra em específico, percebese que esta estratégia é de grande valia, pois consumidores já começam a relacionar a qualidade da informação às possibilidades interativas de sua representação e recuperação.

Além disso os visitantes ressaltaram como favorecedores da percepção da qualidade da informação da exposição, a construção de novos conhecimentos $(7 \%)$, assim como a didática da exposição com informações bem contextualizadas (7\%). Por fim, alguns consumidores chegaram a relatar a possibilidade de recuperação de dados em tempo real com a visitação a exposição (3\%) 0 que também levou a um sentimento de positividade em relação a qualidade da sua informação. Dois exemplos de comentários acerca da qualidade da informação as exposições do Museu do Amanhã seguem abaixo:

Amo museus, e fiquei curiosa para conhecer o Museu do Amanhã. Me deparei com questionamentos que me fizeram pensar profundamente no meu modo de vida e da sociedade em geral. Foram momentos de investimento em conhecimento - do local e de mim mesma (Visitante de Barretos, SP - Agosto, 2018). 
informações sobre a ciência e suas descobertas. É o tipo de museu que se visita mais de uma vez! Adoro! (Visitante de Porto Alegre, RS - Novembro, 2018).

Desse modo, conforme observado na Figura 2, conectando as necessidades funcionais e logísticas de visitação - como a sinalização interna; mapa e folders informativos; site institucional; atendimento de funcionário; clareza das instruções de compra de ingressos, etc. - às prerrogativas da representação e recuperação de informação para a construção do conhecimento social - como a contextualização do acervo; a relevância da informação exposta; a acessibilidade; interatividade; sinergia e didática da expografia, pode-se conseguir - pelo menos em consideração a amostra trabalhada nesta investigação - uma melhoria dos serviços de informação desses espaços, tanto pelo viés da sua infraestrutura, quanto pelo viés expositivo.

Figura 2 - Parâmetros para medição da qualidade da informação em museus

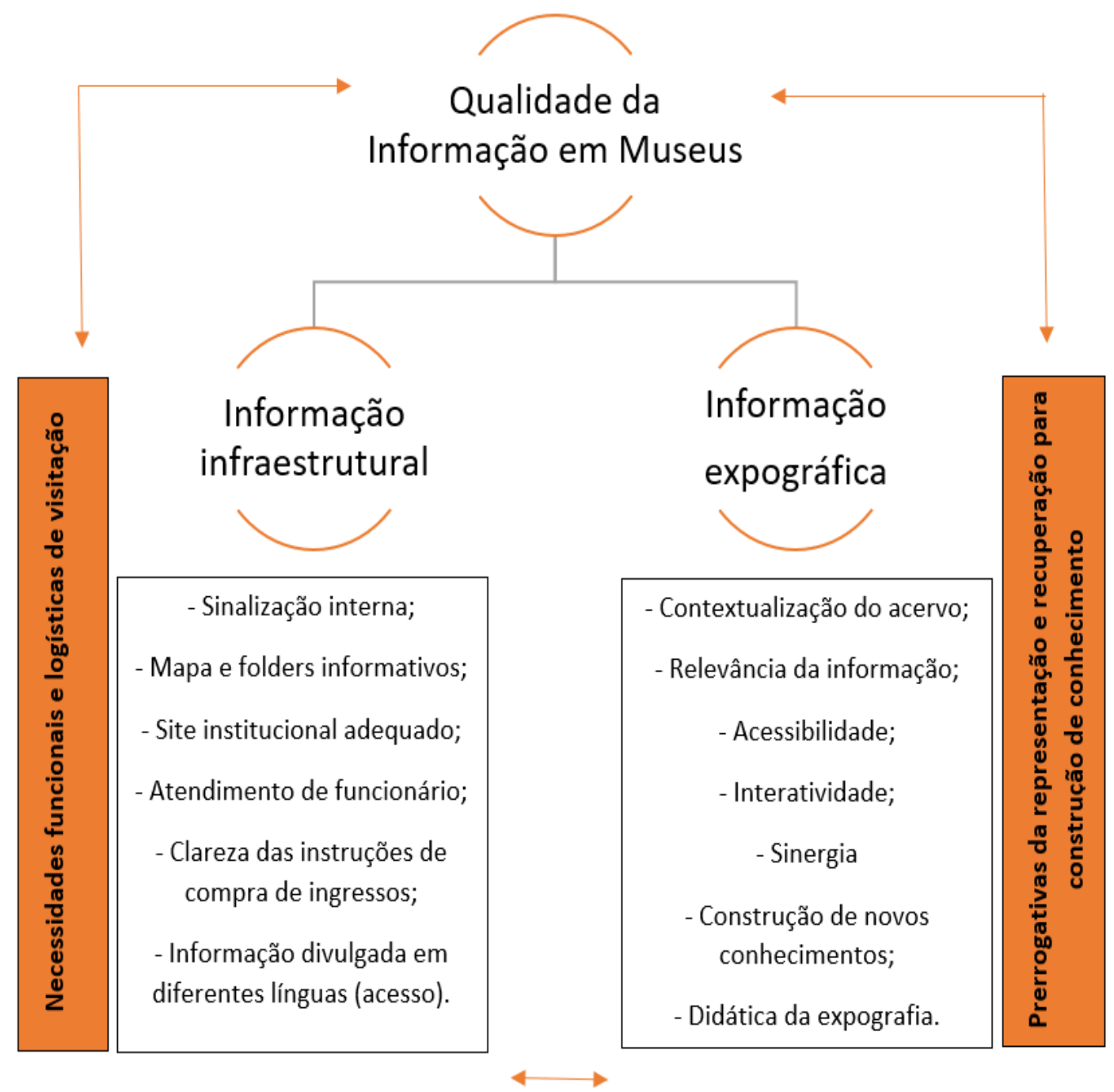

Fonte: Elaboração própria (2019). 


\section{CONSIDERAÇÕES FINAIS}

Conforme se pôde observar com o desenvolvimento teórico desta investigação, 0 atendimento e satisfação da necessidade de informação do consumidor museal perpassa por uma responsabilidade da instituição que deve comunicar, com a devida clareza, todos os serviços ofertados por ela. Nesse sentido, ao tratar a temática da qualidade da informação em museus, a organização deve levar em consideração tanto as necessidades funcionais e logísticas de visitação - ligadas a informação infraestrutural - quanto os sistemas de informação que tangem às prerrogativas da representação $\mathrm{e}$ recuperação para a construção do conhecimento social - ligadas a informação expográfica.

Por esse ângulo, percebe-se como pauta fundamental para os tomadores de decisão em museus, o entendimento da percepção dos seus consumidores quanto a qualidade da informação recuperada através dessas instituições. Por meio de uma pesquisa de análise de sentimento de usuários da plataforma TripAdvisor, foi possível identificar quais aspectos precisam ser melhorados em relação a qualidade da informação do Museu do Amanhã - RJ, mas ainda mais que isso, foi possível determinar parâmetros analíticos em se tratando da temática de estudo, que poderão ser trabalhados por outras instituições museais e seus gestores, podendo contribuir na melhoria dos serviços de informação desses espaços, gerando, quem sabe, alguma vantagem competitiva em relação a outros museus.

Pode-se perceber, nesse sentido, que a opinião postada nas redes é de extrema importância, pois reflete o sentimento sem censura do usuário, o que pode ser entendido como um dos fatores de maior força da metodologia proposta neste artigo. Isso porque, nenhum consumidor fora submetido a aplicação de um questionário ou entrevista, com pauta pré-determinada, pelo contrário, os visitantes foram francos em se tratando das suas próprias experiências dentro do museu estudado, registrando suas opiniões espontaneamente. Por outro lado, devido a pesquisa ter sido realizada através de uma amostra de consumidores não representativa, seus resultados não podem ser generalizados, mas sim, descritos e analisados na tentativa de elevar o conhecimento científico em se tratando da temática qualidade da informação em museus.

Assim, propõe-se para estudos futuros, a aplicação dos passos metodológicos utilizados nesta investigação em museus variados para fins comparativos e criação de novos parâmetros para medição da qualidade da informação em museus. Propõe-se ainda, a inclusão dos próprios gestores museais na discussão dos resultados obtidos, no intuito de serem observadas e tratadas as principais dificuldades enfrentadas na construção e divulgação de informações de qualidade em museus. 


\section{REFERÊNCIAS}

ARAUJO, Matheus. GONÇALVES, Pollyanna. BENEVENUTO, Fabrício. Métodos para Análise de Sentimentos no Twitter. (2013) Disponível em: https://homepages.dcc.ufmg.br/ fabricio/download/ webmedia13.pdf. Acesso: 01/11/2019.

BARRETO, Aldo de Albuquerque. Os agregados de informação - memórias, esquecimento e estoques de informação. DataGramaZero - Revista de Ciência da Informação, v. 1, n., jun. 2000.

BEARMAN, David. "Informação em museus em um contexto social”. In: BEVILACQUA, Gabriel Moore Forell (Org.). II Seminário Serviços de Informação em Museus: 0 trabalho da informação em instituições culturais: em busca de conceitos, métodos e políticas de preservação. Pinacoteca do Estado de São Paulo, São Paulo: Assahi Gráfica e Editora, 2014. p. 39-54.

BEVILACQUA, Gabriel Moore Forell (Org.). II Seminário Serviços de Informação em Museus: 0 trabalho da informação em instituições culturais: em busca de conceitos, métodos e políticas de preservação. Pinacoteca do Estado de São Paulo, São Paulo: Assahi Gráfica e Editora, 2014. 365 p.

CERAVOLO, Suely Moraes. "Museus e geração de informação: embates práticos". In: BEVILACQUA, Gabriel Moore Forell (Org.). II Seminário Serviços de Informação em Museus: 0 trabalho da informação em instituições culturais: em busca de conceitos, métodos e políticas de preservação. Pinacoteca do Estado de São Paulo, São Paulo: Assahi Gráfica e Editora, 2014. p. 81-94.

DUTRA, Larissa Fernandes. BARACHO, Renata Maria Abrantes. Alternativas inteligentes para a preservação do patrimônio cultural no contexto das smart cities. Revista Ibero-Americana de Ciência da Informação. v.13; n..1, 2020. DOI: https://doi.org/10.26512/rici.v13.n1.2020.26210.

GODOY, Karla Estelita. SANCHES, Flavio. "Turistas on-line: produção, distribuição e qualidade das informações para o turismo em museus”. In: BEVILACQUA, Gabriel Moore Forell (Org.). II Seminário Serviços de Informação em Museus: 0 trabalho da informação em instituições culturais: em busca de conceitos, métodos e políticas de preservação. Pinacoteca do Estado de São Paulo, São Paulo: Assahi Gráfica e Editora, 2014. p. 209-219.

GONÇALVES, Pollyanna. ARAUJO, Matheus. BENEVENUTO, Fabrício. CHA, Meeyoung. Comparing and Combining Sentiment Analysis Methods. Disponível em: http://blackbird.dcc.ufmg.br:1210/pdfs/ cosn127-goncalves.pdf. Acesso: 31/10/2019.

JUNIOR, Paulo de Oliveira Lima. Revisão sistemática sobre uso de ontologia para análise de sentimento em conteúdo da web. Ci.Inf., Brasília, DF, v. 44 n. 3, p. 430-443, set/dez. 2015.

MARCHIORI, Patrícia Zeni. "Gestão da Informação: Fundamentos, componentes e desafios contemporâneos". In: SOUTO, Leonardo Fernandes. (Org). Gestão da Informação e do Conhecimento: Práticas e Reflexões. Rio de Janeiro: Editora Interciência, 2014.

MATTERA, Tayane Cristina. "Gestão do Conhecimento na Prática”. In: SOUTO, Leonardo Fernandes. (Org). Gestão da Informação e do Conhecimento: Práticas e Reflexões. Rio de Janeiro: Editora Interciência, 2014. 
MONTEIR0, Juliana. "Desenvolvimento e utilização de sistemas e ferramentas de informação". In: BEVILACQUA, Gabriel Moore Forell (Org.). II Seminário Serviços de Informação em Museus: 0 trabalho da informação em instituições culturais: em busca de conceitos, métodos e políticas de preservação. Pinacoteca do Estado de São Paulo, São Paulo: Assahi Gráfica e Editora, 2014. p. 195201.

Museu do Amanhã, 2019. Disponível em: https://museudoamanha.org.br/pt-br/sobre-0-museu. Acesso: 20/11/2019.

ORTEGA Y GASSET, José. Missão do bibliotecário. Tradução e posfácio de Antonio Agenor Briquet de Lemos. Brasília: Briquet de Lemos, 2006.

SANTOS, Leandro Matioli; ESMIN, Ahmed Ali Abdalla; ZAMBALDE, André Luiz; NOBRE, Frank Mendes. Twitter, análise de sentimento e desenvolvimento de produtos: Quanto os usuários estão expressando suas opiniões? Prisma.com (Portugual), n. 13, p. 159-170, 2010. (Artigo do Contecsi) 29.1810.

LIU, Bing. Sentiment analysis: a multi-faceted problem. IEEE Intelligent Systems, v. 25, n. 3, p. 7680, 2010.

Oliveira, Rafael Almeida de. Extração de dados web como suporte na elaboração de indicadores do turismo de Minas Gerais: uma iniciativa em big data. Dissertação de mestrado: Programa de Pós Graduação em Gestão e Organização do Conhecimento PPG-GOC, Universidade Federal de Minas Gerais, 2017. 88 p. 